\title{
Prazer e sofrimento no trabalho dos líderes religiosos numa organização protestante neopentecostal e noutra tradicional
}

\author{
Ana Magnólia Bezerra Mendes \\ Rogério Rodrigues da Silva ${ }^{1}$
}

\begin{abstract}
Resumo
Objetiva-se mostrar a relação entre as transformações das organizações religiosas e a vivência de prazer e sofrimento de seus líderes. Por sua expressividade no contexto religioso brasileiro e ainda pelas diferenças na estrutura, na hierarquização, na dogmática, nas estratégias de crescimento, estudaram-se duas organizações religiosas protestantes: uma neopentecostal e outra tradicional. Realizaram-se entrevistas semi-estruturadas individuais com 10 líderes de cada uma das organizações. Os resultados apontam em ambas organizações que o prazer está associado a sentimentos de identificação, orgulho, realização e reconhecimento no trabalho. O sofrimento está vinculado ao desgaste físico, emocional, sentimentos de desvalorização, angústia e culpa, podendo ser atribuído à diversidade de atividades, pressão por produtividade, excessiva carga de trabalho, exigência moral, grandes expectativas e lida constante com os problemas psicossociais da comunidade. De maneira geral, observa-se uma vivência de prazersofrimento semelhante a outras profissões, inclusive as formas de enfrentar o sofrimento, com exceção da espiritualização dos problemas.

Palavras-chave: Neopentecostais; Protestantes tradicionais; Prazer-sofrimento.
\end{abstract}

\section{Religious leader's pleasure and suffering at work in a neopentecostal and in a traditional protestant organization}

\begin{abstract}
This study intended to show the impact of the transformation of religious organizations over the pleasure and suffering experiences of their leaders, as well as the way they deal with it, when it exists. Two protestant religious organizations, one neopentecostal and the other traditional, were studied because of their importance in Brazilian religious context as well as their structural differences in hierarchy, dogma, and developing strategies. Individual semi-structured interviews were done with 10 leaders of each organization. The results indicated that pleasure is connected to feelings of identification, pride, realization and recognition at work. Suffering experience is connected to physical and emotional drain, feeling of devaluation, distress and guilt attributed to a diversity of activities, pressure for productivity, excessive work load, moral demand, high expectations and constantly dealing with psychic social community problems. Generally speaking, there are similar levels of pleasure-suffering experiences to other professions, including the way of coping with suffering, with the exception of problems spiritualization.

Keywords: Neopentecostals; Traditional protestants; Pleasure-suffering.
\end{abstract}

\section{Introdução}

As organizações religiosas protestantes têm passado por diversas transformações ao longo dos anos, trazendo como conseqüências, mudanças de paradigmas históricos, influências na sua estrutura e definição dos modos de atuação profissional dos seus líderes. Tais conseqüências são o foco de análise desse artigo, particularmente, as relações entre o modo como o trabalho se insere nessas organizações protestantes e as vivências de prazer e de sofrimento de seus lideres.
As transformações por que passam as organizações religiosas hodiernas podem ser comparadas àquelas observadas no cotidiano secular, cujos objetivos poderiam residir na igual busca do tripé: qualidade, produtividade e eficiência.

A busca desse tripé pode ser atribuída a duas grandes razões. A primeira delas é as transformações do mundo do trabalho, resultantes de uma política de mercado que igualmente atingem as organizações religiosas e que exigem do trabalhador dedicação, competência e eficiência em todas as suas atividades. A segunda razão é a perda de sua importância perante a sociedade, impli-

\footnotetext{
${ }^{1}$ Endereço para correspondência:

Terceira Avenida - Bloco 1.640 n. ${ }^{\circ} 8$ - 71720-020 - N. Bandeirante-DF

Telefone: 613867723 ou 6192845836

Email: psicologo007@gmail.com
} 
cando ações mais agressivas das organizações religiosas na busca por um número maior de fiéis.

$\mathrm{Na}$ situação pluralista de opções religiosas, essas instituições se tornam agências de mercado e as tradições religiosas tornam-se comodities de consumo. Resulta daí uma individuação da atividade religiosa, regulada por uma economia de mercado em que as instituições se assemelhariam àquelas não-religiosas em que se estabelece uma relação de troca. Cada pessoa escolhe a igreja e a religião que mais lhe aprazem.

Essa situação de competição entre as organizações religiosas, própria de uma economia de mercado, inflaciona a importância dos resultados a obter. Num cenário em que há uma diversidade de instituições que também dão sentido à vida, as organizações religiosas competem entre si para conquistar uma maior população de fiéis consumidores. Além disso, mais clara está a aproximação a outras organizações não-religiosas quando se percebe que há também nessas organizações uma produção de bens e serviços para a sociedade. Uma variedade de crenças, programas e itens de serviços são combinados com as necessidades dos "clientes-membros", buscando-se vender produtos que igualmente tenham qualidade, eficiência e produtividade, como em outras organizações não-religiosas. A fé por si só não basta. É preciso satisfazer o cliente e ainda estar antenado às demandas e transformações do mercado (religioso)!

Tal qual no mundo do trabalho atual, como indica Silva (2004), tem-se exigido do líder uma maior flexibilidade na produção, uma variabilidade de competências e atividades, jornadas de trabalho cada vez maiores, decisões cada vez mais dinâmicas e rápidas para enfrentar a demanda dos clientes e, por fim, uma maior produtividade. Não basta ser apenas líder da igreja, é preciso ser também advogado, psicólogo, político, assistente social etc. Não basta ter apenas um culto no domingo, é preciso ter um culto para os jovens, outro para os empresários, outro para os solteiros etc.

Nesse contexto do mercado religioso de cobrança, de produtividade, de busca cada vez maior por qualidade e eficiência é que se ancora o presente estudo. Partindo-se da concepção de que tal contexto também influenciaria a vivência de prazer-sofrimento do líder religioso é que a psicodinâmica do trabalho se mostra um aporte teórico pertinente. Afinal, sob esse contexto haveria mais prazer ou mais sofrimento? E além disso, como esses líderes lidam com o sofrimento porventura vivido?

Para a consecução desta análise, foram selecionadas duas organizações religiosas: neopentecostais e tradicionais. A viabilidade de estudá-las como organizações firma-se na definição apontada por Robbins (2002) em que a organização se caracterizaria com base em uma comunalidade de sentido de objetivos a serem atingidos por um determinado grupo e ainda que há aqui uma produção de bens e serviços, que neste caso assume um caráter simbólico.

Não se pretende aqui fazer uma análise de todo o mercado religioso brasileiro, mas antes propiciar o início de uma discussão sobre prazer e sofrimento em líderes religiosos. Dessa forma, as razões que explicam a escolha dessas organizações são: 1. expressividade de ambas as denominações em número de fiéis no contexto nacional (a tradicional é uma das três maiores denominações do Brasil e a neopentecostal, com um dos maiores canais protestantes a cabo do país, tem crescido muito rapidamente); 2. diferenciação clara entre as denominações, o que possibilitaria uma comparação de resultados, de modo que não seriam contaminados apenas por um único contexto e; 3 . o contato com as organizações foi facilitado, visto que as sedes das duas organizações estão na mesma cidade em que o estudo foi conduzido.

O grupo tradicional, representado pela igreja Batista, conta, segundo Silva (2004), com uma estrutura mais descentralizada de gerenciamento, acarretando maior autonomia ao líder da igreja. Não há aqui uma hierarquia eclesiástica, todavia o poder é determinado pelo tempo de serviço à organização e pelo prestígio da comunidade que se lidera (igrejas em regiões mais centrais e maiores têm um prestígio maior que outras em regiões mais periféricas e com grupos menores de pessoas). Embora haja uma busca eminentemente por um crescimento mais qualitativo da comunidade, percebe-se uma igual cobrança por produtividade e eficiência no trabalho dos líderes por parte da comunidade, considerada aqui como cliente e chefia ao mesmo tempo.

O grupo neopentecostal, representado pela igreja Sara Nossa Terra, segundo Silva (2004), tem uma estrutura mais centralizadora e bastante hierarquizada. A produtividade é baseada numa estrutura moderna de células de produção (bastante parecidas às toyotistas) e daí resultam estratégias de crescimento mais quantitativistas. As estratégias de crescimento baseiam-se em três pilares básicos: a) teologia da prosperidade; b) guerra espiritual e; c) uso intensivo da mídia, principalmente a televisão.

Esses pilares são, sob um processo de "reencantamento" do mundo, uma nova oferta dessas igrejas neopentecostais do milagre, do mistério e da magia, apontados por Berger (1985) como os elementos mais antigos e poderosos do sagrado. A guerra espiritual enquadra-se na perspectiva de que os conflitos da vida cotidiana, tais como miséria e doenças, são explicados a partir da ação maligna na 
vida do fiel e seriam superados mediante uma luta espiritual.

A teologia da prosperidade oferece uma promessa de bem-estar, saúde, vitória, felicidade e prosperidade financeira mediante os canais do dízimo e das ofertas à igreja. Por fim, a utilização intensiva da mídia possibilita a popularização da igreja, tornando-a acessível a grandes massas. Tais pilares tornam-se meios eficazes de proselitismo, de obtenção de novos negócios e membros, de avanço político e até de status para a organização religiosa.

Tomando por base essas considerações organi-zacionais e dogmáticas das igrejas escolhidas, partimos então para a análise do impacto das transformações e diferenças do contexto de produção sobre as vivências de prazer e sofrimento no trabalho de seus líderes.

A análise do contexto de trabalho constitui-se como conceito fundamental para a compreensão do impacto da relação entre organização (religiosa) e sociedade e, além disso, da dinâmica da organização do trabalho desses líderes religiosos. Esse contexto, segundo Ferreira e Mendes (2003), é constituído por três aspectos, quais sejam: a organização do trabalho, as condições de trabalho e as relações socioprofissionais. Compreendendo o que e por que é feito, com o que é feito e com quem é feito, poder-seia melhor relacionar o impacto desse novo contexto organizacional religioso sobre as vivências de prazer e sofrimento na atividade do líder religioso.

A organização do trabalho se refere às regras, normas, foco da produtividade e divisão do trabalho que demonstra a identidade da organização e a forma de lidar com seus processos organizacionais. As condições de trabalho se referem à infra-estrutura oferecida para a realização das atividades, bem como suas práticas de recursos humanos. Por último, as relações socioprofissionais estabelecidas se referem ao aspecto relacional entre pares, chefia e clientes (considerados aqui como "clientes-membros") possibilitam a análise da organização com a sociedade. São essas dimensões, ao serem avaliadas de forma negativa ou positiva pelo trabalhador, as responsáveis pelo desencadeamento das vivências de prazer ou de sofrimento.

O prazer é proveniente da gratificação pulsional, resultante da consonância entre a subjetividade do trabalhador (sonhos, desejos, anseios) e o que é oferecido pelo contexto de trabalho (Dejours, Abdoucheli \& Jayet, 1994; Mendes \& Cruz, 2004). Vários seriam os indicadores de prazer no trabalho: valorização, reconhecimento, liberdade, realização, gratificação, orgulho no trabalho, capacidade de aprendizagem,

Psico-USF, v. 11, n. 1, p. 103-112, jan./jun. 2006 sentido no trabalho. Neste estudo, serão considerados apenas os indicadores reconhecimento e liberdade. Para Ferreira e Mendes (2003), o reconhecimento está relacionado aos sentimentos de valorização, orgulho e identificação com a atividade. Já o sentimento de liberdade está associado à possibilidade de pensar, falar e agir sobre a atividade.

O sofrimento está vinculado a sentimentos como angústia, medo e insegurança, provenientes do conflito entre as necessidades de gratificação e a restrição de satisfazê-las impostas pelas limitações das situações de trabalho. O sofrimento pode ser expresso por meio de sentimentos como ansiedade, insatisfação, solidão, inutilidade, desvalorização e desgaste. Neste estudo, contudo, utilizar-se-ão como indicadores de sofrimento os sentimentos de desvalorização e desgaste. O sentimento de desvalorização é definido, segundo Ferreira e Mendes (2003), como o sentimento de insegurança e incompetência do trabalhador perante questões de produtividade e desempenho. Já o desgaste está ligado a sentimentos de cansaço, stress, desânimo, sobrecarga e frustração.

Para não ocorrer uma desestruturação e desequilíbrio mental diante das incertezas, das insatisfações e do sofrimento resultantes das situações de trabalho, as estratégias de mediação tornam-se fundamentais para transformá-los ou negá-los. Segundo Mendes e Cruz (2004), essas estratégias podem ser defensivas ou de mobilização subjetiva.

As defesas utilizadas pelos trabalhadores, de modo geral, atende ao mesmo tempo uma lógica sociopsíquica e de racionalidade econômica, gerando alianças implícitas, que podem não permitir o confronto das contradições dos modos de produção e conseqüentemente, de um enfrentamento das situações de adversidades. Nesse sentido, a defesa contribui de alguma forma para aceitação do sofrimento mental gerado pela organização capitalista do trabalho e conseqüentemente gera um imobilismo social diante das questões coletivas da categoria profissional.

A mobilização subjetiva é uma estratégia que possibilita a ressignificação do sofrimento a partir da modificação da realidade que faz sofrer. Tal mobilização se sustenta no coletivo de trabalho, por meio do aspecto público de discussão, socialização do sofrimento, da cooperação e coesão grupais.

Não obstante, quando essas estratégias falham, o trabalhador pode ser levado ao adoecimento e aparecimento de doenças como depressão, DORT como apresentado por Rocha (2003), em estudo com bancários afastados do trabalho.

Nessa perspectiva, a abordagem da psicodinâmica do trabalho é privilegiada nesse estudo, conside- 
rando a pergunta central dessa pesquisa de como os lideres religiosos de organizações protestantes neopentencostais e tradicionais vivenciam o seu trabalho, tendo como parâmetro a análise do contexto de trabalho, que ao longo dos anos vem se transformando e imprimindo uma nova lógica de funcionamento e estruturação.

\section{Método}

\section{Participantes}

O presente estudo foi realizado com 20 líderes religiosos de organizações do Distrito Federal, sendo 10 da organização neopentecostal e 10 da tradicional.

No grupo neopentecostal, os líderes tinham em média 39,72 anos (DP $=7,15)$, a maioria do sexo masculino $(92,9 \%)$, com tempo médio de denominação de 4,51 anos (DP 3,82) e cerca de $23 \%$ dos sujeitos tinha um curso superior completo. Já para o grupo dos tradicionais, os líderes tinham em média 44,26 anos (DP = 9,64), todos do sexo masculino, com tempo médio de denominação de 13,95 anos $(\mathrm{DP}=9,51)$ e cerca de $62 \%$ dos sujeitos apresentavam curso superior completo.

\section{Instrumentos}

A entrevista individual semi-estruturada se mostrou como instrumento válido para o estudo, visto flexibilidade e possibilidade de abordar conteúdos relacionados à dinâmica do trabalho e experiências individuais. Além disso, a entrevista semi-estruturada centrase na pessoa e com a qual, o entrevistador, numa atitude de empatia, se desenvolve segundo a lógica do próprio entrevistado, a partir de temas diretamente relacionados ao estudo (Bardin, 1977).

Foram, então, realizadas vinte entrevistas (dez para cada grupo) com duração média de sessenta a noventa minutos. Nas entrevistas foram abordados os seguintes temas: descrição do trabalho (organização, condições e relações de trabalho), sentimentos em relação ao trabalho, dificuldades encontradas no trabalho e as estratégias para lidar com as mesmas.

\section{Procedimentos}

O primeiro passo foi obter a permissão dos presidentes das organizações para a realização da pesquisa. A partir daí foi obtida uma relação de todos os líderes das denominações e assim houve uma seleção aleatória dos participantes. Procurou-se entrevistar líderes de todas as hierarquias das denominações a fim de possibilitar uma visão mais geral da organização e para verificar diferenças nas percepções de prazer e sofrimento.

\section{Análise de Dados}

A análise dos dados pautou-se numa análise qualitativa, utilizando a análise de conteúdo (Bardin, 1977). As entrevistas foram analisadas por três juízes utilizando técnica categorial temática indutiva, todos acadêmicos de psicologia. A partir de uma leitura flutuante das entrevistas foram realizadas análises das coocorrências dentro dos critérios: representatividade, exaustividade e homogeneidade. Com o material codificado e as co-ocorrências das falas numa mesma entrevista, extraíram-se as relações entre os elementos das falas e a partir daí a construção de categorias. Elaboradas as categorias específicas de cada uma das entrevistas e com as co-ocorrências de seu conjunto, foram definidas as categorias síntese.

\section{Resultados}

As categorias síntese das dez entrevistas realizadas com o grupo dos tradicionais foram as seguintes:

1) Ser líder é muito cobrado. A diversidade de atividades exige grande produtividade e jornada de trabalho excessiva dos líderes.

2) O líder está completamente desamparado. Há uma percepção de falta de suporte, sensação de desproteção, principalmente quando o líder está desempregado.

3) Somos muito menos unidos do que deveríamos. Com outros líderes e clientes-membros, o relacionamento é percebido como sendo fraterno, amistoso, todavia, a autonomia entre as igrejas gera uma competição velada e um certo distanciamento entre líderes.

4) O que a igreja decidir para ela é lei. Não há homogeneidade quanto à organização das igrejas. A hierarquia é apenas representativa, não tendo qualquer poder de influência sob a igreja local.

5) O primeiro pensamento é de angústia pelas coisas que tem que fazer. Há uma crise psíquica gerada pelo pouco suporte oferecido, exigência de boa conduta moral e cobrança constante por resultados por parte da igreja. Essa crise gera frustração, cansaço, esgotamento, irritação e culpa quando os objetivos não são alcançados. A superação da crise se dá com a busca religiosa, com o diálogo com outros líderes e a realização de atividades físicas e de lazer e hobby.

6) Não faria outra coisa a não ser, ser pastor. Há um forte sentimento de realização e identificação, referindo-se principalmente ao fato de poder ajudar e servir as pessoas. 
A análise de conteúdo das dez entrevistas do grupo dos neopentecostais revelou as seguintes categorias síntese:

1) Temos metas de células, quanto mais tivermos, mais forte fica o corpo. As metas são claras e difíceis de serem alcançadas. São orientadas para resultados e crescimento quantitativo, gerando uma grande pressão e ainda são percebidas como desafios e oportunidades para o aperfeiçoamento.

2) O ministério tem isso muito forte, protege o lider. São oferecidos aos líderes treinamentos, novas metodologias de trabalho, assistência psicológica e financeira, o que gera uma sensação de segurança. O apoio oferecido, contudo, depende do tempo de vinculação à organização, fidelidade e produtividade do líder. As recompensas baseiam-se no crescimento numérico e financeiro da comunidade local.

3) Não temos uma estrutura para estarmos mais perto das pessoas, estamos mais perto de nossos lideres. $\mathrm{O}$ relacionamento com os superiores é bom e próximo, tal qual com os pares, embora existam zonas de conflito. Com os clientes-membros, o relacionamento é mais distanciado, ora se sentindo valorizado pelo trabalho, ora não.

4) É o conselho de bispos, eles estabelecem qual vai ser 0 andamento. A igreja se estrutura em redes de células de produção. A estrutura organizacional é bastante hierarquizada, com uma clara divisão entre aqueles que planejam e os que executam.

5) O desgaste natural, físico mental e psicológico? Tudo isso acontece mesmo! Os problemas e dificuldades são colocados apenas para a chefia para que não haja uma desestruturação organizacional e porque só ela tem o poder de resolução. Há um ambiente de pressão. O desgaste gerado é superado com atividades físicas, terapia, lazer e busca religiosa.

6) É um sentimento de realização muito grande. $\mathrm{O}$ trabalho é visto como sendo importante para as pessoas e para a sociedade. Há também um grande orgulho de fazer parte da organização e ocupar o cargo atual.

Observa-se de maneira geral que as organizações se estruturam de maneira bem diferente, contudo em ambas se percebem forte pressão por produtividade, forte sentimento de realização e desgaste dos líderes. As igrejas tradicionais são heterogêneas; têm maior autonomia e liberdade e o relacionamento entre pares são mais distanciados. Já entre os neopentecostais, há indicação de uma maior hegemonia de ações e discurso. Com a igreja dividida em células, há uma forte hierarquização, principalmente no que se refere ao planejamento e à execução das atividades.

Embora existam indícios de uma vivência mais forte de prazer, o sofrimento também é bastante pre-

Psico-USF, v. 11, n. 1, p. 103-112, jan./jun. 2006 sente. O prazer está ligado essencialmente à possibilidade de servir as pessoas gerando uma clara realização e o sofrimento ao desgaste físico e psíquico, cujo enfrentamento se dá de maneira diferenciada.

\section{Discussão}

Como pode ser observado com base nas entrevistas, há diferenciações estruturais, mas também semelhanças entre as organizações estudadas e aquelas não-religiosas. Parte disso pode ser atribuído a uma nova relação estabelecida entre igreja e sociedade em que o processo de secularização (Berger, 1985) se tornou ponto essencial. A competição com outras estruturas de explicação da vida, segundo o autor, impõe novas estruturas, novos meios de gerenciar, novas tecnologias às organizações religiosas atuais.

Várias seriam as diferenças entre essas organizações. Enquanto que entre os batistas há uma estruturação de poder mais burocrático, entre os saristas, há uma dinâmica de poder pautado no carisma, ligado, segundo a ótica weberiana, a uma atribuição de poder e qualidade sobrenatural, resultando no bem-estar da comunidade. Dessa estruturação pode estar relacionada a clara diferença no grau de escolarização observado. Enquanto a tradicional exige de seus líderes uma formação teológica superior (cerca de $62 \%$ de seus líderes têm ensino superior completo), entre os neopentecostais (cujo mesmo índice não chega a $25 \%$ ) a exigência para subir na carreira eclesiástica se dá pelo reconhecimento da própria comunidade, mas principalmente pela hierarquia no tocante à produtividade e qualidade do trabalho do líder.

Para Enriquez (2000), em organizações estratégicas definidas a partir da grande utilização de planejamento de curto prazo e pela grande adaptabilidade de modelos resultante das ações e circunstâncias criadas pelos adversários e parceiros, como entre os neopentecostais, são necessários indivíduos capazes de tomar iniciativas, de reagir rapidamente, de trabalhar em equipes, de ter conhecimentos mais superficiais em áreas diversas. Tal cenário está bem próximo ao observado entre os neopentecostais. Além disso, pode explicar também a diferença do nível de escolarização e a grande exigência por resultados quantitativos dos neopentecostais. Como jogadores que tentam ganhar e obter sucesso em curto prazo, há pouco tempo para formação, para relações mais profundas e para um trabalho com maior qualidade.

Estar mais perto dos líderes e não das pessoas, como observado nos neopentecostais é uma indicação dessa posição estratégica. Para Siepierski (2000), essa distância dos membros é uma forma de reforçar a auto- 
ridade central da hierarquia, na medida em que não se criam laços horizontais com e entre os membros. Assim, a política e as ações da organização não estariam sendo contaminadas ou em risco. A perpetuação carismática do poder estaria dessa forma mais garantida.

$\mathrm{Na}$ estrutura burocrática do grupo tradicional, o controle se dá pelo expertise. Nessas organizações o controle está mais ligado à qualidade da relação estabelecida com a comunidade, mostrando-se mais descentralizado e individualizado. Entre os neopentecostais, o controle volta-se para uma maior racionalidade da produção: "É o conselho de bispos, eles estabelecem qual vai ser o ordenamento". É preciso pensar apenas no bem da organização, de modo que urge a necessidade de uma uniformização do pensamento organizacional, idealizar a organização, traduzida na capacidade do convencimento de bem falar, saber, convencer, sorrir e seduzir (Enriquez, 2000). Decorre daí uma relação mais próxima à chefia que dos clientes-membros, como observada na categoria 3 dos neopentecostais.

A percepção das metas como desafios a serem constantemente superados, apontada pelos neopentecostais, insere-se numa auto-realização em que o carismatismo e a teatralidade da liderança são pontos essenciais. Para Freitas (2000), esse tipo de organização desperta sentimentos contraditórios de prazer e sofrimento, levando o indivíduo a amar as próprias dificuldades, a amar a organização, com o nome de desafios e a procurar dominá-las, anestesiando, dessa forma, parte do sofrimento vivido.

Eu uso esse termo aqui na igreja que os nossos bispos são a nossa fonte...Eu preciso beber deles, en preciso estar junto deles...Porque eles é que são a fonte da igreja local. O sucesso da igreja local depende das nossas vidas aos nossos bispos (líder neopentecostal).

Um outro aspecto a se considerar é a estruturação, peculiar aos neopentecostais, de rede celular de produção. Estrutura mais flexível para as demandas do mercado, como aponta Silva (2004), essas células de produção repassam para toda a comunidade a responsabilidade do apoio social, da captação de recursos, da integração de novos membros, da produção dos bens religiosos. Nessa gestão celular, tal como no modelo toyotista, os líderes das células também têm como atribuição (Antunes, 1999; Heloani, 2003; Silva, 2004): motivação do grupo, planejamento, organização e cuidado com a qualidade dos produtos (qualidade das pregações, dos eventos promovidos etc); identificação das necessidades de treinamento e desenvolvimento; discussão do desempenho (aqueles que não produzem são chamados a explicar o mau desempenho); cuidado nas questões disciplinares. O líder neopentecostal se torna, dessa forma, um grande gerente. Destarte, o modelo celular adotado facilita o desenvolvimento do trabalho, o sucesso, a cobrança, a vinculação com a organização e, ainda, o crescimento funcional na organização.

Nós temos equipes, temos departamentos que sistematicamente se reúnem para pensar, avaliar, estabelecer novas metas de células, então isso é uma coisa que a estrutura está de acordo com os conceitos modernos (líder neopentecostal).

No tocante às relações estabelecidas, nos dois grupos analisados, percebe-se uma vivência de sentimentos dúbios entre chefia, pares e clientes. Tristezas, remorsos, alegrias, reconhecimentos, ansiedades, dúvidas estão presentes nessas relações. Contudo, o que se observa, principalmente entre os tradicionais, é o pouco espaço para o estabelecimento de um vínculo maior entre pares, resultando numa maior socialização do sofrimento enfrentado. A estrutura autônoma de cada igreja cerceia a possibilidade da troca interpessoal com outros lideres, do apoio, do espaço para discussão daquilo que faz sofrer, fundamental para a transformação de sofrimento em prazer, segundo Ferreira e Mendes (2003).

A despeito da dubiedade das relações com os clientes, outro espectro de análise se lança: a transcedentalidade da relação cliente-consumidor. Pautada principalmente numa relação servil, herança judaicocristã do trabalho religioso, essa relação com a comunidade possibilita o desenvolvimento de reconhecimento e de valores como integridade, honestidade, liberdade e justiça (Korac-Kakabadse, Kouzmin \& Kakabadse, 2002), resultando em níveis maiores de identificação e realização pessoal para ambas as organizações religiosas. Além disso, essa relação cria para o trabalhador não somente uma relação racional "dar-receber", mas possibilita uma maior integração entre indivíduo e organização e entre este e a sociedade, com base na visualização do impacto de suas atividades.

Valendo-se desse contato com os clientesmembros, o reconhecimento no trabalho surge como oportunidade de construir a identidade pessoal e social desses trabalhadores (Merlo, 2002; Mendes \& Cruz, 2004). Fundamental para essa busca identitária no trabalho, esse contato parece validar as qualidades e originalidades do trabalho da liderança. Além disso, a partir desse reconhecimento, simbólico ou real, o trabalho passa a ter não somente um significado pessoal, mas importa também a toda a organização e também para a sociedade. 
É uma realização muito grande, estou podendo fazer parte de uma história. Estou fazendo parte da história do meu país, de uma geração que vai estar mudando, crescendo. Isso é uma realização muito grande" (líder neopentecostal).

Além do reconhecimento, o forte sentimento de realização se faz claro e bastante intenso entre esses líderes. Essa realização está diretamente ligada ao sentido que o trabalho assume para esses líderes: servir à comunidade e cumprir a vocação divina. Sob a égide de uma nova perspectiva das relações de troca com a sociedade, o caráter vocacional e sacerdotal da liderança religiosa é (ainda) um forte componente na estruturação do sentido desse trabalho. Diferente de outras profissões como professor e médico, essa vocação do líder religioso, que tem um caráter fortemente divinizado, poderia ser ainda fonte de contradição entre valores pessoais e o contexto organizacional, principalmente no que se refere à ambígua decisão entre crescer a organização ou contribuir com a comunidade, todavia esse aspecto não foi mencionado nas entrevistas, sugerindo estudos posteriores.

A identificação com a atividade e a idealização da organização, verificadas principalmente entre os neopentecostais, podem conduzir paradoxalmente a uma maior subordinação e submissão. Isso se deve princi-palmente aos limites impostos à consciência e realização pessoal, que dariam o toque original ou criativo ao trabalho (Antunes, 1999; Heloani, 2003). Imaginar a atividade como sendo um bem divino e a organização como sempre boa e grande provedora pode limitar as possibilidades de mudanças e, até mesmo, a própria satisfação do sujeito. $\mathrm{Na}$ posição de grande provedora, a organização dilui o conflito trabalho-capital e reafirma a necessidade de submissão dos trabalhadores à lógica abstrata de dominação inconsciente do capital (e até mesmo divina!), cujos objetivos máximos são produção e lucro a partir de uma promessa de ser a fonte de reconhecimento, amor e identidade, podendo preencher e curar as imperfeições e fragilidades dos trabalhadores (Freitas, 2000; Heloani, 2003).

Embora existam fortes indicadores de prazer, o sofrimento é verificado nesses líderes a partir da forte incidência de desgaste físico e psicológico. A constante lida com problemas psíquicos e sociais da comunidade, a forte exigência moral e a constante disponibilidade para as pessoas trazem sérias conseqüências, principalmente pelo parco espaço público de discussão e pelo fraco apoio organizacional, principalmente entre os tradicionais. Este parco suporte social acarreta uma vivência mais solitária, individualista entre os tradicio- nais. Entre os neopente-costais a possibilidade de socialização do sofrimento é igualmente limitada, porém maior, a partir de reuniões periódicas entre os líderes, contudo, há um risco iminente de "desestabilizar a estrutura" se há outros conteúdos pessoais, como pode ser observado na fala.

\section{Claro que eu nunca vou procurar conversar esse tipo de assunto com o meu par, porque eu vou colocar um sentimento meu (frustração). Se estiver fažendo isso, vou estar o contaminando com um sentimento que é meu e gerando um problema pra estrutura (líder neopentecostal).}

Relacionada também ao sofrimento, a sensação de culpa e fracasso foi apontada em ambos os grupos. Para Enriquez (2000), a idealização da organização e da atividade fomentaria esse sentimento de culpa e vergonha. Sob a performance da excelência, cada indivíduo, segundo o autor, prova da vergonha quando não se mostra à altura da organização ideal, quando não chega a realizar seus objetivos e a se superar. Além da culpa gerada entre esses líderes por não atingir os objetivos propostos, existe outra faceta dessa culpa: a divinização da atividade. Não cumprir as metas propostas é também, para esses líderes, não cumprir o dever incumbido por Deus, como aponta Silva (2004). Não basta cumprir as exigências da organização e da comunidade, tem que cumprir a (con)vocação divina!

\section{A impressão é que a gente sempre está vivendo num pro- cesso de culpa constante, porque não consegue fazer isso, aquilo.. A gente enfatiza muito mais aquilo que não fez que aquilo que já fizemos. Isso gera uma culpa muito grande. Faz um estrago mesmo. Um sentimento de angústia e insegurança terrivel no coração (líder tradicional).}

Como num jogo, de ganhos e perdas, o prazer não se desvincula do sofrimento também entre esses líderes religiosos. O sofrimento, mesmo no ambiente de trabalho, pode se tornar uma via para renovação. $\mathrm{O}$ stress, o tédio, o cansaço, a tristeza podem se tornar oportunidades para construção de uma nova obra, de um novo momento. A vida laboriosa não precisa ser feita de um estado de pleno gozo, mas pode ser vivenciada a partir da transformação da situação que faz sofrer (Mendes, 1999; Enriquez, 2000). É uma oportunidade de refazer, de criar, de flexibilizar, de transformar, de deixar sua marca no mundo.

Enfrentar o sofrimento como uma oportunidade de transformação envolve o processo de mobilização, que ganha entre esses líderes um caráter muito 
mais individual que coletivo, segundo Silva (2004). Embora sozinhos, esses líderes desenvolvem suas próprias estratégias defensivas contribuindo para estabilizar sua relação com a organização do trabalho e até mesmo impedir um desequilíbrio psíquico.

Entre os neopentecostais há uma tendência maior para encarar o sofrimento como uma oportunidade de superação. Como aponta Silva (2004), nesse grupo a ilusão do desafio e superação, como observada nas entrevistas, anestesia o sofrimento, dando-lhes um sentimento de plenitude, de conquista, recalcando certos desejos e, até mesmo, negando outros aspectos da realidade.

Entre os tradicionais, o individualismo se mostra como uma das estratégias de superação do sofrimento. Apontado por Jayet (1994) como uma estratégia de defesa, é resultante da falta de cooperação, do compartilhamento de regras e também pela desestruturação das relações psicoafetivas com o coletivo de trabalho. A descentralização hierárquica e a autonomia da comunidade quebram a possibilidade de uma relação profissional mais próxima, de maior confiança, eqüidade, normas e valores compartilhados com líderes. Além de servir como estratégia defensiva esse individualismo, que parece atingir também os neopentecostais, presta-se igualmente para a manutenção da imagem mítica de líder, visto a socialização de fraquezas e sofrimentos, perder-se-ia sua aura divinizada da liderança.

Os resultados apontam ainda para outro tipo de defesa, chamada de atividades compensatórias. Essas atividades surgem como válvulas de escape, assumindo caráter essencial de compensar o sofrimento (Silva, 2004). Fugindo ao domínio direto do contexto de trabalho, não são realizadas naquele contexto, mas em sua razão. Descanso, lazer, hobbies, atividades lúdicas fora do trabalho assumem líderes de ambos os grupos um grande valor para enfrentar o sofrimento.

Por fim, outra estrutura defensiva contra o sofrimento é a religiosidade. Compreendida aqui como uma busca humana do sagrado, do divino, do transcendente, a religiosidade é inerente à própria atividade desses líderes e não como mais uma atividade que extrapola seu contexto. Para Silva (2004), não apenas como saída para o sofrimento, mas também como uma possibilidade de dar um sentido à vida, a religiosidade se mostra como uma forma eficiente de fugir do desprazer e encontrar o prazer no trabalho, embora não seja suficiente para evitar o sofrimento. A possibilidade de vivenciar valores pessoais na organização e, além disso, facilitar um contato maior com o outro e com o divino, dariam à religiosidade uma outra utilidade que não apenas o de afirmações ou promessas.
Essa angústia tem que espiritualizar mesmo...pode ser resolvida com coração aberto e rasgado diante de Deus (líder tradicional).

\section{Conclusão}

As transformações organizacionais e dogmáticas da igreja, inseridas numa guerra (não declarada) do mercado religioso em que as instituições religiosas se tornam agências de mercado e as tradições, discursos e práticas religiosos em bens para o consumo (Berger, 1985) exigem cada vez mais do líder, seja para se manter no mercado, seja para obter melhores resultados. Dessa forma, ser apenas um pregador dominical não basta. Tem que ser também um bom vendedor de bens simbólicos ou reais. As transformações não atingem apenas os aspectos observáveis das organizações, mas outros tantos invisíveis à própria sociedade gerando sofrimento no trabalho.

Pertencer a uma organização religiosa e ainda viver praticamente 24 horas diárias um preceito religioso, que, em princípio, serviria como fonte de prazer, não exime esses líderes de vivenciarem igualmente $\mathrm{o}$ sofrimento. $\mathrm{O}$ que geraria prazer, também tem gerado sofrimento. Os resultados apontaram que, de maneira geral, o prazer no trabalho desses líderes está vinculado a sentimentos de identificação, realização e reconhecimento. Já o sofrimento está vinculado ao desgaste físico, desgaste emocional, sentimento de desvalorização, angústia e culpa cujas razões poderiam ser: a diversidade de atividades, excessiva carga de trabalho, exigência moral, grandes expectativas da comunidade e lida constante da problemática psíquica e social da comunidade. E para lidar com esse sofrimento, são utilizadas estratégias diferentes entre os grupos, mas todas de cunho individualizado, diminuindo a possibilidade da socialização do sofrimento de modo a auxiliar na sua mediação e na sua transformação do contexto que faz sofrer.

As principais limitações do presente estudo apontam para duas direções. A primeira delas é o pequeno número de participantes e tipo de organizações, que ora pode ser minimizado pela característica que o estudo assume: um estudo exploratório. Numa indicação de continuidade do estudo, outras organizações religiosas poderiam ser comparadas, enriquecendo a análise do trabalho de seus líderes.

A segunda limitação é a fluidez entre religião e o trabalho dos líderes religiosos. Religião e trabalho se mostraram como conceitos muito fluidos em que não se sabia o que era realmente trabalho e o que era parte da religião. Contudo, pautou-se por uma análise que se 
referia à religião como parte do trabalho e a sua influência sobre o contexto de produção.

Pretendeu-se, mesmo que minimamente, colaborar com uma discussão sobre o impacto das transformações do mundo do trabalho na atividade dos líderes das atuais organizações religiosas. A busca (frenética) de crescimento organizacional, ora com um caráter mais qualitativo, ora mais quantitativo, distancia os grupos analisados quanto a sua estrutura e até mesmo da forma como enfrentar as influências e pressões do mercado religioso, mas ao mesmo tempo as aproxima de outras várias organizações não-religiosas, principalmente no que tange à busca do tripé: qualidade, produtividade e eficiência. Isso pode ser verificado pela análise do prazer e sofrimento que apontou grandes semelhanças de suas percepções a outros estudos de líderes não religiosos, como feirantes, gerentes, bancários, engenheiros (Mendes, 1999; Rocha, 2003; Mendes \& Cruz, 2004) que ora também sofrem pressões por resultados, desgaste e para isso utilizam-se das mesmas formas de lidar com o sofrimento. Afinal, a religião parece não sustentar por completo o sofrimento advindo do trabalho. É preciso mais que isso.

\section{Referências}

Antunes, R. (1999). Os sentidos do trabalho. Ensaio sobre a afirmação e negação do trabalho. São Paulo: Boitempo.

Bardin, L. (1977). Análise de conteúdo. Lisboa: Edições 70.

Berger, P. L. (1985). O Dossel Sagrado. Elementos para uma teoria sociológica da religião. São Paulo: Paulus.

Dejours, C., Abdoucheli, E. \& Jayet, C. (1994). Psicodinâmica do Trabalho: contribuições da escola dejouriana à análise da relação prazer, sofrimento e trabalho. São Paulo: Atlas.

Enriquez, E. (2000). O indivíduo preso na armadilha da estrutura estratégica. Em F. C. P. Motta \& M. E. Freitas (Orgs.). Vida psíquica e organização (pp. 23-40). Rio de Janeiro: FGV.

Ferreira, M. C. \& Mendes, A. M. (2003). Trabalho e Riscos de Adoecimento: o caso dos Auditores-Fiscais da Previdência Social Brasileira. Brasília: Ler, Pensar, Agir.

Freitas, M. E. (2000). A questão do imaginário e a fronteira entre cultura organizacional e a psicanálise. Em
F. C. P. Motta \& M. E. Freitas (Orgs.). Vida Psíquica na Organização (pp. 41- 73). Rio de Janeiro: FGV.

Heloani, R. (2003). Gestão e organização no capitalismo globalizado. História da manipulação psicológica no mundo do trabalho. São Paulo: Atlas.

Jayet, C. (1994). Psychodynamique du travail au quotidien. Paris: Alexitére.

Korac-Kakabadse, N., Kouzmin, A. \& Kakabadse, A. (2002). Spirituality and leadership praxis. Journal of Managerial Psychology, 17 (3), 165-182.

Mendes, A. M. (1999). Valores e vivências de prazer-sofrimento no contexto organizacional (Tese de Doutorado). Brasília: Universidade de Brasília.

Mendes, A. M. \& Cruz, R. M. (2004). Trabalho e saúde no contexto organizacional: vicissitudes teóricas. Em A. Tamayo (Org.). Cultura e saúde nas organizaçôes (pp. 39 - 55). Porto Alegre: Artmed.

Merlo, A. R. C. (2002). Psicodinâmica do Trabalho. Em M. G. Jacques \& W. Codo (Orgs.). Saúde Mental \& Trabalho (pp. 130-142). Petrópolis: Vozes.

Robbins, S. (2002). Comportamento Organizacional. São Paulo: LTC.

Rocha, S. R. A. (2003). "O pior é não ter mais profissão, bate uma tristeza profunda": sofrimento, distúrbio osteomoleculares relacionados ao trabalho e depressão em bancários (Dissertação de Mestrado). Brasília: Universidade de Brasília.

Siepierski, C. T. (2000). "De bem com a vida": O sagrado num mundo em transformação. Um estudo sobre a Igreja Renascer em Cristo e a presença evangélica na sociedade brasileira contemporânea (Tese de Doutorado). São Paulo: Universidade de São Paulo.

Silva, R. R. (2004). Profissão Pastor: prazer e sofrimento. Uma análise psicodinâmica do trabalho de líderes religiosos neopentecostais e tradicionais (Dissertação de Mestrado). Brasília: Universidade de Brasília.

Sobre os autores:

Ana Magnólia Bezerra Mendes é professora do Departamento de Psicologia Social e do Trabalho do Instituto de Psicologia da Universidade de Brasília e doutora em Psicologia Social e do Trabalho pela Universidade de Brasília. 
Rogério Rodrigues da Silva é professor da Faculdade Projeção Brasília. Mestre em Psicologia Social e do Trabalho pela Universidade de Brasília, tem desenvolvido estudos sobre a questão do prazer e sofrimento no trabalho e os impactos do modelo gerencial baseado em espiritualidade no trabalho. 